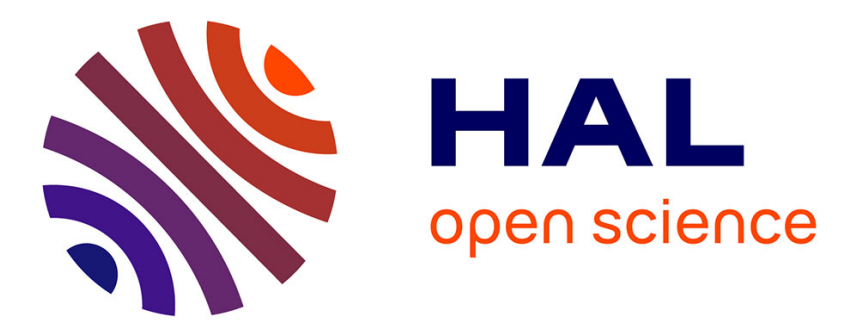

\title{
Unified isothermal and non-isothermal modelling of neat PEEK crystallization
}

\author{
Emeline Bessard, Olivier de Almeida, Gérard Bernhart
}

\section{To cite this version:}

Emeline Bessard, Olivier de Almeida, Gérard Bernhart. Unified isothermal and non-isothermal modelling of neat PEEK crystallization. Journal of Thermal Analysis and Calorimetry, 2014, 115 (2), p. 1669-1678. 10.1007/s10973-013-3308-8 . hal-01611997

\section{HAL Id: hal-01611997 \\ https://hal.science/hal-01611997}

Submitted on 11 Jan 2019

HAL is a multi-disciplinary open access archive for the deposit and dissemination of scientific research documents, whether they are published or not. The documents may come from teaching and research institutions in France or abroad, or from public or private research centers.
L'archive ouverte pluridisciplinaire HAL, est destinée au dépôt et à la diffusion de documents scientifiques de niveau recherche, publiés ou non, émanant des établissements d'enseignement et de recherche français ou étrangers, des laboratoires publics ou privés. 


\title{
Unified isothermal and non-isothermal modelling of neat PEEK crystallization
}

\author{
Emeline Bessard • Olivier De Almeida • \\ Gérard Bernhart
}

\begin{abstract}
A differential generalized Avrami's law is used to model crystallization kinetic of PEEK in considering that PEEK crystallization results from the contribution of two distinct mechanisms. The form of this equation allows to predict with good accuracy both isothermal and nonisothermal crystallization kinetics. Nevertheless, isothermal model parameters are not entirely satisfactory for predicting non-isothermal crystallization and the identification of kinetic parameters is needed for both isothermal and non-isothermal cases. The results show that the Avrami exponents and Arrhenius activation energies remain constant for both conditions and therefore suggest that these parameters are only material dependent. On the other hand, the other kinetic parameters depend on the crystallization condition and vary with temperature and/or cooling rate.
\end{abstract}

Keywords PEEK · Crystallization · Kinetic modelling · Differential scanning calorimetry (DSC)

\section{Introduction}

In the field of thermoplastic composite materials, PEEK is an interesting alternative to conventional epoxy matrices used in aeronautical industry because of its higher impact resistance and chemical compatibility to aeronautical

E. Bessard · O. De Almeida ( $₫)$ · G. Bernhart

Institut Clément Ader (ICA), Université de Toulouse, Mines Albi, Campus Jarlard, Route de Teillet, 81013 Albi Cedex 09, France

e-mail: olivier.dealmeida@mines-albi.fr

URL: http://www.institut-clement-ader.org/ fluids. Nevertheless a high degree of crystallinity (over 35 mass $\%$ ) must be guaranteed to ensure optimal mechanical performances $[1,2]$. In order to increase the use of such materials in structural application new rapid manufacturing processes are under investigation like the thermo-compression of powdered or commingled fabrics, using induction heated die technology [3].

The understanding of the physicochemical phenomena of polymer crystallization allows a better control and optimisation of industrial processes. Therefore, the improvement of simulation possibilities has motivated large developments of crystallization models for semicrystalline polymers, and many extensions of Avrami's crystallization law were proposed to accurately describe this material transformation.

The work of J. W. Gibbs, based on a classical thermodynamical concept, extended by Turnbull and Fischer [4] and later by Hoffman and Lauritzen [5] to polymer has first allowed to justify the crystallization of semi-crystalline thermoplastic as a two main step process: nucleation and crystal growth. Models based on Avrami equation provide a well prediction of crystallization but are in general limited to isothermal crystallization.

Nakamura [6] and Ziabicki [7] extended the Avrami equation to predict non-isothermal crystallization kinetics using isothermal transformation data. Ozawa [8] also proposed another extension of Avrami model where kinetic parameters depend on cooling rate. Nevertheless, even if they provide good correlations with experimental data, these models are still limited to uniform cooling rate conditions. In order to describe complex cooling paths, Patel and Sprueill [9] first proposed a differential form of the Nakamura model that is more compatible and useful for thermal modelling [10]. This differential form was also used by Malkin et al. [11] who assumed that the crystallization rate is the sum of 
two differential forms respectively related to nucleation and crystal growth. Polymer crystallization was mostly modelled by these various approaches. Nevertheless, they are no longer accurate when polymers exhibit unusual crystallization behaviour.

Among the different thermoplastics, poly-ether-etherketone (PEEK) can exhibit multiple melting peaks depending on the cooling conditions, which confirm that classical models may be inaccurate to predict crystallization kinetics.

In particular, a double melting peak appears when crystallization occurs at high temperature (isothermal conditions) or at low cooling rates. The main melting peak corresponds to the classical theory of nucleation and subsequent crystal growth, and the corresponding crystallization is very well described by classical macroscopic laws of Avrami, Tobin, Malkin Urbanovici-Segal [12].

The origin of the secondary melting peak is however still discussed. One of the interpretation, reported by Lee and Porter and by Blundell and Osbourn [13, 14], supposes that the crystals with the low melting temperature form first and then transform into another crystal structure showing a higher melting temperature during annealing or heating.

However, the results of a previous work argue in favour of two melting peaks coming from separate populations of crystals, the higher melting peak related to the primary crystals and the lower melting peak to secondary crystals which may grow between the original crystals [15]. This point of view of PEEK crystallization agrees with the description proposed by many authors and this paper considers this explanation as a starting point for the present work [15-19].

Therefore, as long as two distinct phases are considered, the fusion enthalpy related to this secondary peak significantly increases the absolute degree of crystallinity of PEEK. Models able to predict this complex crystallinity rate of PEEK are thus required. Velisaris and Seferis [20] first proposed a new model for isothermal crystallization of PEEK: they combined two standard Avrami models to take into account two competing crystallization processes. Cebe later extended this approach to non-isothermal conditions using an Hoffman-Lauritzen approach [21].

Compared to previous work, this paper proposes an unified modelling based on a double differential JMA model that is adapted to the kinetic modelling of neat PEEK crystallization and suitable for the prediction of both isothermal and non-isothermal crystallization kinetics. Special emphasis is put on model parameters identification. The identified parameters are then discussed as long as this double differential JMA model well describes the crystallisation process of two populations that is reported in the literature [15-19].

\section{Experimental investigation of PEEK crystallization}

\section{Materials and experiments}

The material under investigation is a PEEK provided by Victrex as a powder with the reference 151G. The crystallization kinetics were studied by differential scanning calorimetry (DSC) with a Perkin-Elmer 8000 equipment. The DSC sealed caps were prepared with 1-1.5 mg of PEEK powder. This low mass allowed considering negligible heat transfer effects when applying cooling rates up to $100 \mathrm{~K} \mathrm{~min}^{-1}$. Moreover, in order to start cooling from a nuclei-free melt, the samples were systematically heated from room temperature to $400{ }^{\circ} \mathrm{C}$ and held for $5 \mathrm{~min}$ in the molten state.

Isothermal crystallization conditions were achieved by quickly cooling the sample at $200{ }^{\circ} \mathrm{C} \mathrm{min}{ }^{-1}$ from the molten state to isothermal crystallization temperature (Tiso). The sample was then kept at Tiso for $15 \mathrm{~min}$ and cooled again quickly to room temperature. Non-isothermal crystallization conditions were carried out using constant cooling rates between 3 and $100{ }^{\circ} \mathrm{C} \mathrm{min}{ }^{-1}$. For each test condition, the transformation rate was assessed from the crystallization heat flux by the partial area method.

All the crystallized samples were subjected to a heating ramp of $10{ }^{\circ} \mathrm{C} \mathrm{min}{ }^{-1}$ from room temperature to $400{ }^{\circ} \mathrm{C}$ to determine the mass fraction crystallinity in considering a reference enthalpy of fusion of $130 \mathrm{~J} \mathrm{~g}^{-1}$ [22].

Isothermal crystallization results

Eight isothermal temperatures were investigated between 290 and $310^{\circ} \mathrm{C}$. Repeatability was ensured by performing three tests for each temperature (except for $290{ }^{\circ} \mathrm{C}$ ).

The relative mass crystallinity is plotted as a function of time in Fig. 1 for four different temperatures. It can be seen that PEEK crystallization is a continuous process: no sudden changes or discontinuities are discernible in the curves. The sigmoidal shape is characteristic of the overall crystallization of all homopolymers and reveals evidence of nucleation and growth processes.

The crystallization duration depends on testing temperature. For an equivalent transformation rate, the lower the temperature, the higher the crystallization kinetic is, i.e. if crystallization at $310{ }^{\circ} \mathrm{C}$ occurs within 6 min this duration drops to $<1 \mathrm{~min}$ at $300{ }^{\circ} \mathrm{C}$.

Figure 2 illustrates the endothermic curves of polymer fusion measured after isothermal crystallization at 302 and $305^{\circ} \mathrm{C}$ : the PEEK fusion systematically displays a double peak already reported in the literature $[15,16,23,24]$. The main melting peak temperature is $343{ }^{\circ} \mathrm{C}$ whatever isothermal temperature investigated during the cooling stage. It corresponds to the fusion of the orthorombic crystalline 


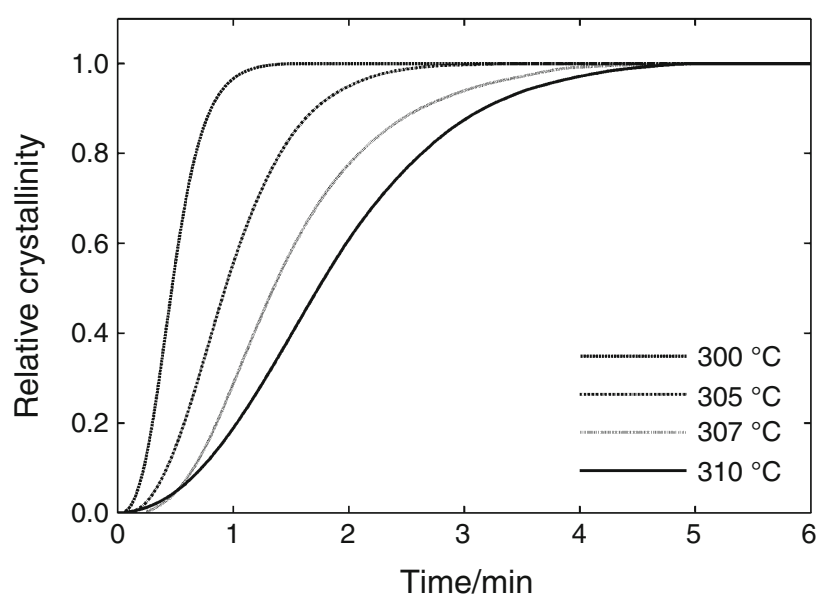

Fig. 1 Isothermal crystallization kinetics

phase of PEEK and it is assumed to be the main melting temperature afterwards called $T_{\mathrm{m} 1}$ [20,21]. The maximum temperature of the secondary melting peak, afterwards called $T_{\mathrm{m} 2}$, appears at lower temperature. As already observed for example by Tan et al. [22], this peak is consistently $6-7{ }^{\circ} \mathrm{C}$ above the temperature of the isothermal crystallization step. For example, an isothermal crystallization at $305{ }^{\circ} \mathrm{C}$ induces a secondary melting peak at $312{ }^{\circ} \mathrm{C}$.

Insofar we consider the two melting peaks as coming from separate populations of crystals, this low temperature peak must be taken into consideration when calculating the total degree of crystallinity $X_{\mathrm{m}}$. Under such condition, the procedure consists in performing a deconvolution of the peaks and to consider two different reference enthalpies of fusion when calculating the degree of crystallinity.

This procedure is, however, not necessary for PEEK. Indeed, WAXS experiments performed in a previous study on PEEK samples demonstrated that both crystal

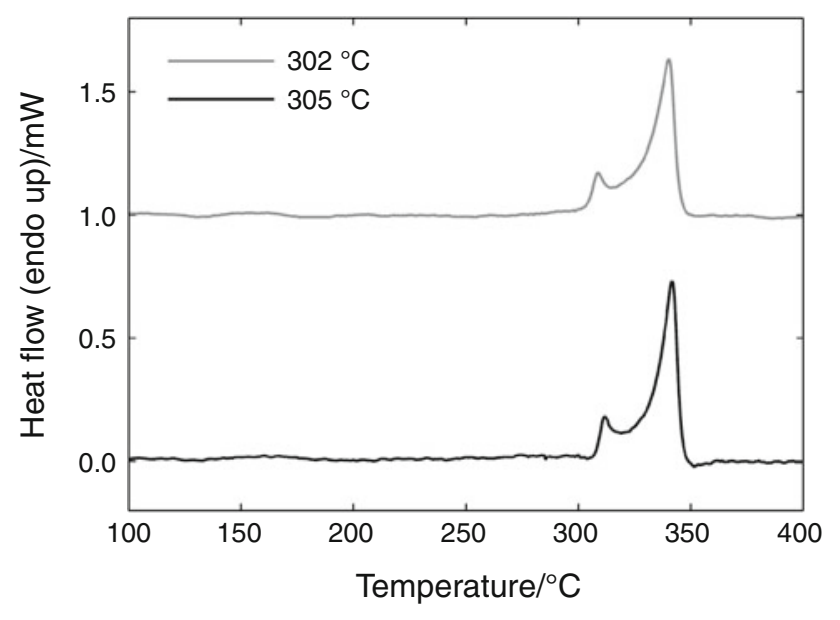

Fig. 2 DSC melting curves of neat PEEK crystallized at 302 and $305{ }^{\circ} \mathrm{C}$ populations correspond to the same crystalline structure [14]. As a consequence, an identical enthalpy of fusion for both phases can be assumed, which agrees with the methodology used by many authors [17].

Table 1 summarises the enthalpy of fusion and the resulting degree of crystallinity obtained for the eight different test conditions. Taking this double peak into account ensures a large degree of crystallinity, above 34 mass\% for all investigated test conditions as shown in Table 1 , and an isothermal step at $304{ }^{\circ} \mathrm{C}$ leads to the highest degree of crystallinity of 39 mass\%. Moreover, the estimated Standard Deviation of the three different tests is low and confirms the methodology used.

Non-isothermal crystallization results

The total enthalpy of fusion and resulting degree of crystallinity measured for the nine constant cooling rates investigated between -3 and $-100{ }^{\circ} \mathrm{C} \min ^{-1}$ are reported in Table 2. The results are consistent with the influence of cooling rate reported for all homopolymers, i.e. when cooling rate increases the amount of crystallinity decreases. For all investigated configurations, the values are lower than after isothermal conditions and the lowest value is 26 mass \% for $-100{ }^{\circ} \mathrm{C} \min ^{-1}$.

Relative crystallinity curves are plotted in Fig. 3 for increasing cooling rates. As reported for isothermal crystallization, the variation exhibits a sigmoidal shape with a maximal crystallization rate at half-time crystallization. Figure 3 also shows that the temperatures of crystallization start $\left(T_{\text {start }}\right)$, peak $\left(T_{\text {peak }}\right)$ and end $\left(T_{\text {end }}\right)$ are strongly dependent on the cooling conditions. As shown in Fig. 4, crystallization occurs between 310 and $240{ }^{\circ} \mathrm{C}$ and all these three temperatures decrease when increasing cooling rate whereas the crystallization range $\Delta T_{\text {crys }}$ increases. For instance, $T_{\text {start }}$ (resp. $\Delta T_{\text {crys }}$ ) moves from $307{ }^{\circ} \mathrm{C}$ (resp $32{ }^{\circ} \mathrm{C}$ ) at $-10^{\circ} \mathrm{C} \min ^{-1}$ to $287^{\circ} \mathrm{C}$ (resp $47^{\circ} \mathrm{C}$ ) at $-100{ }^{\circ} \mathrm{C} \mathrm{min}^{-1}$. Error bars indicate that if start and peak temperatures are reproducible, crystallization end

Table 1 Enthalpies of fusion and degree of crystallinity for different isothermal crystallization temperatures

\begin{tabular}{llll}
\hline Tiso $/{ }^{\circ} \mathrm{C}$ & $\Delta H / \mathrm{J} \mathrm{g}^{-1}$ & Standard deviation & $X_{\mathrm{m}} / \mathrm{mass} \%$ \\
\hline 290 & 45.1 & - & 34.6 \\
300 & 47.9 & 1.6 & 36.6 \\
302 & 48.8 & 2.6 & 37.5 \\
304 & 51.2 & 1.2 & 39.3 \\
305 & 47.1 & 0.3 & 36.2 \\
307 & 47.2 & 1.9 & 36.4 \\
308 & 47.6 & 0.8 & 36.6 \\
310 & 49.2 & 0.7 & 37.8 \\
\hline
\end{tabular}


Table 2 Enthalpies of fusion and degree of crystallinity for different cooling rates

\begin{tabular}{lll}
\hline Cooling rate $/{ }^{\circ} \mathrm{C} \mathrm{min}^{-1}$ & $\Delta H / \mathrm{J} \mathrm{g}^{-1}$ & $X_{\mathrm{m}} / \mathrm{mass} \%$ \\
\hline-3 & 47.4 & 36.5 \\
-5 & 46.0 & 35.4 \\
-7 & 44.1 & 33.9 \\
-10 & 37.4 & 28.8 \\
-20 & 37.6 & 28.9 \\
-40 & 36.8 & 28.3 \\
-60 & 37.8 & 29.1 \\
-80 & 34.8 & 26.7 \\
-100 & 33.8 & 26.0 \\
\hline
\end{tabular}

temperature fluctuates around the average value with an amplitude of $5^{\circ} \mathrm{C}$.

The melting curves resulting from cooling at $-3,-10$ and $-60{ }^{\circ} \mathrm{C} \mathrm{min}^{-1}$ are displayed in Fig. 5. In opposition to isothermal crystallization, only a single melting peak appears for high cooling rates. It corresponds to the main peak observed previously at the same temperature of $343{ }^{\circ} \mathrm{C}$ and designated as $T_{\mathrm{m} 1}$. However, on melting curves of slowly cooled samples $\left(<10^{\circ} \mathrm{C} \mathrm{min}^{-1}\right)$, a shoulder is observable at the beginning of fusion and indicates that a secondary mechanism contributes to crystallization.

\section{Kinetic modelling and identification}

Kinetic model description

The isothermal crystallization kinetics are usually studied using Avrami's law where $\alpha(t)$ is the relative crystallinity as a function of time $t, X(t)$ is the crystallised fraction at time $t$ and $X(\propto)$ is the volume crystalline fraction for infinite time at temperature $T$ [25]. Applied to polymers,

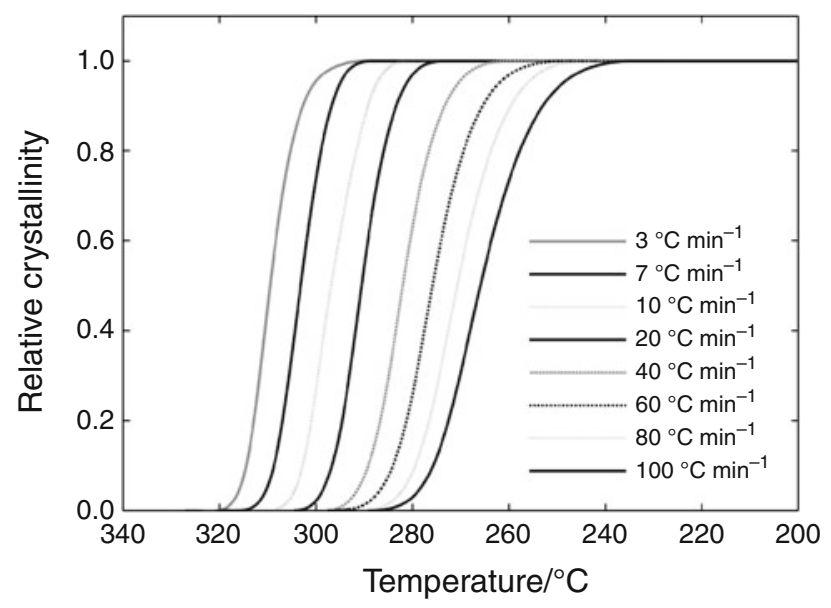

Fig. 3 Non-isothermal crystallization kinetics of neat PEEK

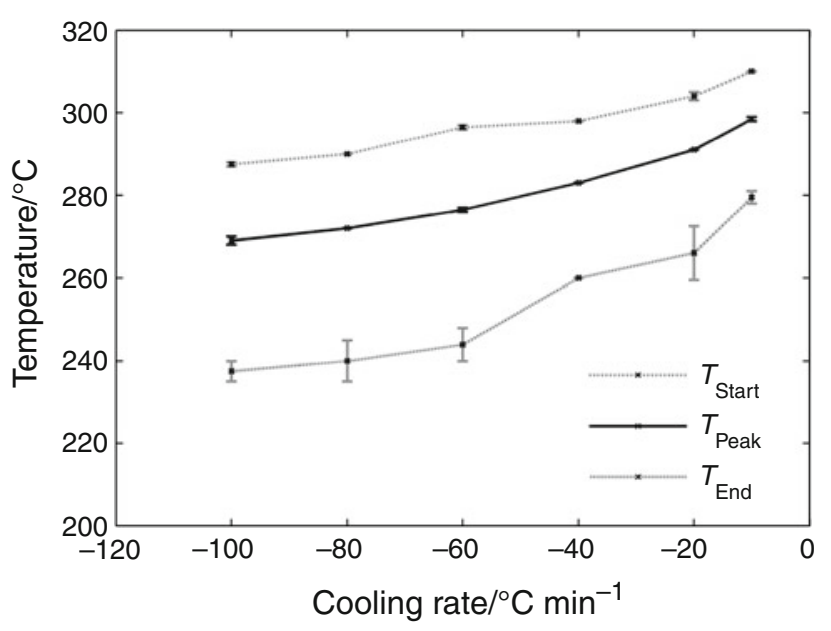

Fig. 4 Variation of characteristic crystallization temperatures with cooling rate

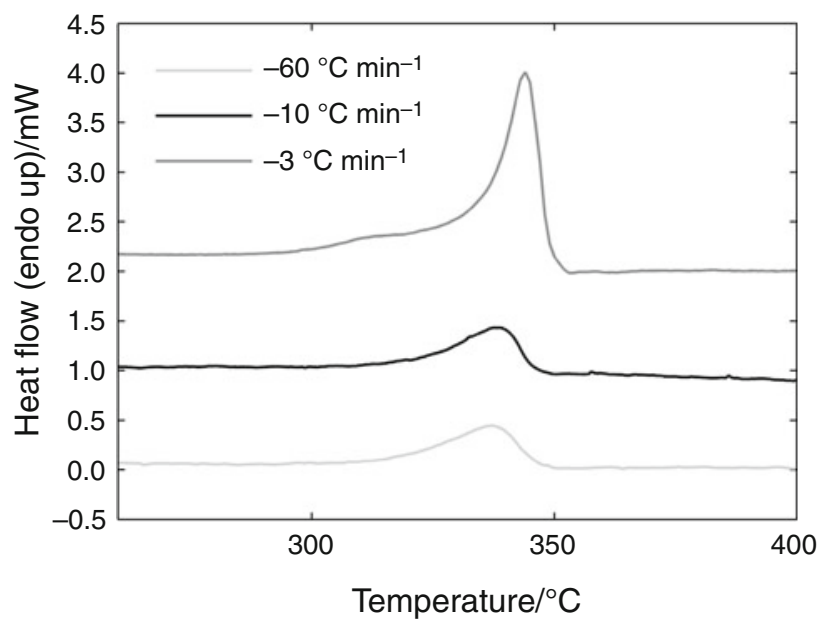

Fig. 5 DSC melting curves resulting from crystallization at different constant cooling rates $\left(-3,-10\right.$ and $\left.-60{ }^{\circ} \mathrm{C} \mathrm{min}^{-1}\right)$

the exponent n (Avrami exponent) contains some information about the type of nucleation while $K$ characterizes the crystallization growth rate $\left(\mathrm{s}^{-1}\right)$ and depends on the isothermal testing temperature.

$\alpha(t)=\frac{X(t)}{X(\infty)}=1-e^{-\mathrm{Kt}^{\mathrm{n}}}$

Generally, for studying the non-isothermal crystallization kinetics, Nakamura or Tobin models based on the Avrami's law, where $\mathrm{K}\left(\mathrm{s}^{-\mathrm{n}}\right)$ depends on cooling rate, are used [4, 26, 27]. These models give a very good correlation with experiments; nevertheless they cannot describe simultaneously isothermal, non-isothermal or complex cooling paths. Their application is thus limited to monotonic cooling conditions.

In order to model isothermal and non-isothermal polymer crystallization kinetics with a unique model, the JMA (Jonhson-Mehl-Avrami) equation is used (Eq. 2) [27]. 
This form, based on the generalized form of the Avrami equation (Eq. 3), was first introduced for polymers by Patel and Sprueill and used later by different authors [7, 28]. It allows in principle the prediction of non-isothermal crystallization using isothermal data.

$$
\begin{aligned}
& \dot{\alpha}=n K(1-\alpha(t)) \ln \left(\frac{1}{1-\alpha(t)}\right)^{\frac{\mathrm{n}-1}{\mathrm{n}}} \\
& \alpha(t)=\frac{X(t)}{X(\infty)}=1-e^{-(\mathrm{Kt})^{\mathrm{n}}}
\end{aligned}
$$

Referring to applicability of JMA model discussed by Malek, it appears that this simple modelling approach is not consistent with experimental results [27]. As a matter of fact Fig. 6 shows no linearity when plotting the double logarithmic plot $\ln \left(\ln \left(1-\frac{X_{\mathrm{m}}(t)}{X_{\mathrm{m}}(\infty)}\right)\right)$ versus $\ln (t)$, in particular for isothermal condition or slow cooling rates $\left(<10^{\circ} \mathrm{C} \mathrm{min}{ }^{-1}\right)$ for which a secondary mechanism contribution is observed (double melting peak).

Velisaris and Seferis, Cebe and Wei observed similar behaviour in indicating two typical slopes initially equal to

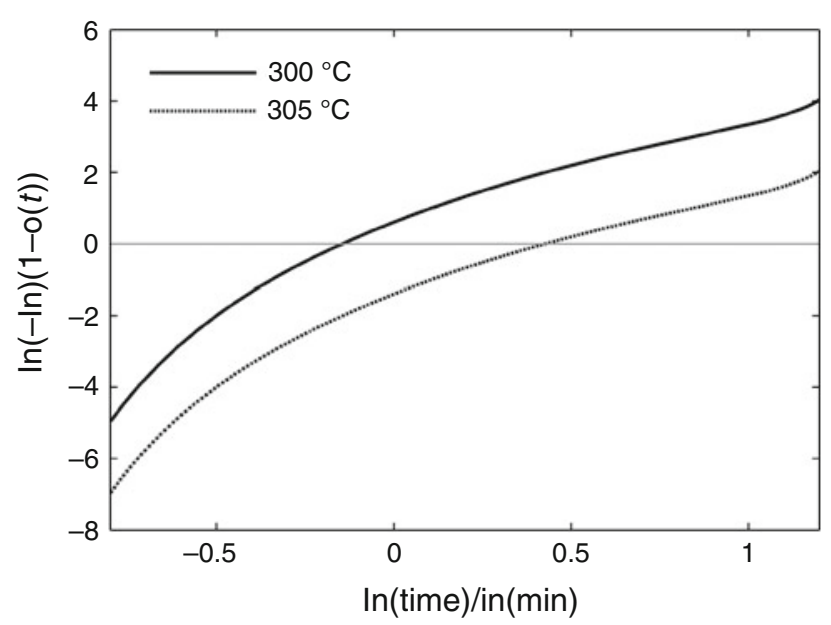

Fig. 6 Avrami crystallization plot for isothermal crystallization of neat PEEK at $305^{\circ} \mathrm{C}$
2.5 and changing to $1.5[20,21,24]$. This bilinear behaviour was related by Velisaris and Seferis to be a consequence of the existence of two parallel crystallization mechanisms: the first main crystallization was associated to the main endothermic melting peak $T_{\mathrm{m} 1}$, whereas the second was associated to a secondary crystallization corresponding to the minor endothermic peak $T_{\mathrm{m} 2}$ (Fig. 2).

In order to consider the simultaneous contribution of two complementary mechanisms and using the time independent Eq. 2, the total crystallization rate can be modelled with Eq. 4 where $i=1$ (resp. $i=2$ ) corresponds to main (resp. minor) crystallization mechanism. Each crystallization process is associated to a weighting factor, respectively $w_{1}$ and $w_{2}$, with $w_{1}+w_{2}=1$.

$\dot{\alpha}=\sum_{\mathrm{i}=1}^{2} w_{\mathrm{i}} \underset{\mathrm{i}}{\dot{\alpha}}=\sum_{\mathrm{i}=1}^{2} w_{\mathrm{i}} n_{\mathrm{i}} K_{\mathrm{i}}\left(1-\alpha_{\mathrm{i}}(t)\right) \ln \left(\frac{1}{1-\alpha_{\mathrm{i}}(t)}\right)^{\frac{\mathrm{n}_{\mathrm{i}}-1}{\mathrm{n}_{\mathrm{i}}}}$

Isothermal identification

Previous crystallization model using two competing mechanisms requests the identification of five parameters $w_{1}, K_{1}, K_{2}, n_{1}, n_{2}$. Identification was performed using a numerical optimisation procedure developed in Matlab ${ }^{\circledR}$; it compares isothermal DSC results with the numerical integration of Eq. 4 using Runge-Kutta method. Because mechanism 1 is related to the main crystallization process, upper and lower bounds of $w_{1}$ were set respectively to 1 and 0.5 but $n_{1}, n_{2}, K_{1}$ and $K_{2}$ parameters were considered free during optimisation.

As reported in Table 3, the procedure leads to reproducible results, indicating a stable optimization procedure. Moreover, the values of the different parameters agree with the literature: the order of magnitude of crystallization kinetic parameters $K_{1}$ and $K_{2}$ is similar to the those reported by Velisaris or Cebe, and $n_{1}$ and $n_{2}$ are respectively close to 2.1 and 1.7 , i.e. between the upper and lower bounds of 1 and 4 suggested by the Avrami theory [20, 21].

\begin{tabular}{|c|c|c|c|c|c|c|c|c|}
\hline \multirow[t]{2}{*}{$T /{ }^{\circ} \mathrm{C}$} & \multirow[t]{2}{*}{$n_{1}$} & \multirow[t]{2}{*}{$n_{2}$} & \multirow[t]{2}{*}{$K_{1} / \times 10^{-2}$} & \multirow[t]{2}{*}{$K_{2} / \times 10^{-2}$} & \multirow[t]{2}{*}{$w_{1}$} & \multicolumn{3}{|c|}{ Standard deviation } \\
\hline & & & & & & $K_{1} / \times 10^{-4}$ & $K_{2} / \times 10^{-4}$ & $w_{1}$ \\
\hline 290 & 2.10 & 1.70 & 6.00 & 1.5 & 0.98 & - & - & - \\
\hline 300 & 2.10 & 1.70 & 3.13 & 1.47 & 0.95 & 5.25 & 4.08 & 0.00 \\
\hline 302 & 2.10 & 1.69 & 2.32 & 1.30 & 0.95 & 3.30 & 13.6 & 0.00 \\
\hline 304 & 2.09 & 1.70 & 1.60 & 1.03 & 0.93 & 0.00 & 6.00 & 0.03 \\
\hline 305 & 2.10 & 1.70 & 1.50 & 0.89 & 0.89 & 0.00 & 10.0 & 0.00 \\
\hline 307 & 2.10 & 1.70 & 1.09 & 0.70 & 0.82 & 2.50 & 1.00 & 0.04 \\
\hline 308 & 2.10 & 1.68 & 1.05 & 0.75 & 0.76 & 11.10 & 13.6 & 0.09 \\
\hline 310 & 2.10 & 1.70 & 0.82 & 0.63 & 0.84 & 0.25 & 3.00 & 0.04 \\
\hline
\end{tabular}

Table 3 Results of isothermal kinetic model parameter identification 
Indeed, the exponents $n_{1}$ and $n_{2}$ are found constant, whatever the testing temperature between 290 and $310{ }^{\circ} \mathrm{C}$ ( $n_{1}=2.1$ and $\left.n_{2}=1.7\right)$. The $n$ exponent that is characteristic of crystallization type (nucleation and growth) would thus not be influenced by temperature.

Contrary to the Avrami exponent, as Table 3 indicates, the weighting factor w1 varies according to isothermal temperature: in increasing temperature from 290 to $308{ }^{\circ} \mathrm{C}$, $w_{1}$ decreases from 0.98 to 0.76 . It indicates that the main crystallization process has a strong contribution on total crystallization but also that the contribution of secondary crystallization mechanism is more important when temperature is high (where crystallization kinetic is low).

Kinetic parameters $K_{1}$ and $K_{2}$ are largely influenced by temperature as well, but the sensitivity of parameter $K_{\mathrm{i}}$ with respect to temperature is more important than for $K_{2}$ : $K_{1}$ (resp. $\left.K_{2}\right)$ decreases from $6 \times 10^{-2}\left(\right.$ resp. $1.5 \times 10^{-2}$ ) to $0.82 \times 10^{-2}$ (resp. $0.63 \times 10^{-2}$ ) when increasing temperature of isothermal crystallization from 290 to $310{ }^{\circ} \mathrm{C}$. Moreover, the identified values reveal that kinetic parameter $K_{1}$ is always higher than $K_{2}$, even if both parameters exhibit a same order value at high temperature.

$K_{\mathrm{i}}(T)=A_{\mathrm{i}} \exp \left(-\frac{E_{\mathrm{i}}}{R\left(T_{\mathrm{m}}-T\right)}\right)$

The temperature dependence of kinetic parameters $K_{1}$ and $K_{2}$ can be modelled with an Arrhenius law assuming that crystallization is thermally activated. In Eq. 5 the kinetic parameters are expressed as a function of the surfusion $T_{\mathrm{m}}-T$, in considering a melting temperature $T_{\mathrm{m}}$ of $343{ }^{\circ} \mathrm{C}$. Each kinetic parameter $K_{\mathrm{i}}$ is characterized by an activation energy $E_{\mathrm{i}}\left(\mathrm{J} \mathrm{mol}^{-1}\right)$ and a pre-exponential factor $\left(A_{\mathrm{i}}\right)$.

The identified values of $E_{\mathrm{i}}$ and $A_{\mathrm{i}}$ are reported in Table 4, and the Arrhenius models calculated with these values are displayed in Fig. 7. One can see that the model shows a good fitting with experimental values. Both activation energies and pre-exponential factors are in good agreement with the respective decrease of $K_{1}$ and $K_{2}$. Indeed, the pre-exponential factor $A_{\mathrm{i}}$ that relates the order of magnitude of the mechanism kinetic is greater for mechanism 1, which kinetic is faster. Similarly, the fact that $E_{1}>E_{2}$ is not surprising, since the activation energy reflects the sensitivity to surfusion and therefore to temperature. Furthermore, it can be noticed that the activation energy of the main mechanism $E_{1}$ is close to the value previously reported by Cebe [29].

Table 4 Constant Arrhenius parameters identified for each crystallization mechanism of neat PEEK

\begin{tabular}{|c|c|c|}
\hline & Mechanism 1 & Mechanism 2 \\
\hline$E_{\mathrm{i}} / \mathrm{J} \mathrm{mol}^{-1}$ & 1,316 & 1,050 \\
\hline$A_{\mathrm{i}}$ & 0.91 & 0.26 \\
\hline
\end{tabular}

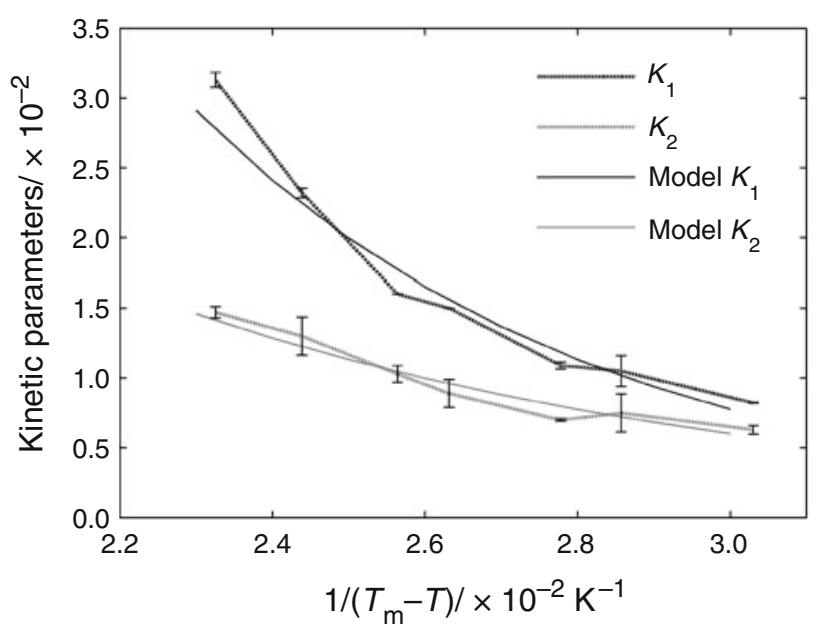

Fig. 7 Variation of kinetic parameters $K_{1}$ et $K_{2}$ as a function of temperature

Figure 8 show the good correlation between experiment and modelling for two temperatures 305 and $310^{\circ} \mathrm{C}$. For both crystallization temperatures, the main first mechanism related as $\alpha_{1}$ occurs in the early stage of crystallization, while secondary mechanism $\alpha_{2}$ is delayed and its contribution to crystallization becomes substantial just before $\alpha_{1}$ reaches its maximal contribution. In isothermal conditions, the first mechanism thus largely influences the first part of the $S$-shape curve while the second one has major influence on the end of crystallization kinetics. The consequence is the dissymmetry of the sigmoidal kinetic curve as reported in the experimental section.

Non-isothermal modelling

In a first attempt, isothermal data were used to simulate nonisothermal crystallization of PEEK. For this purpose, a non-

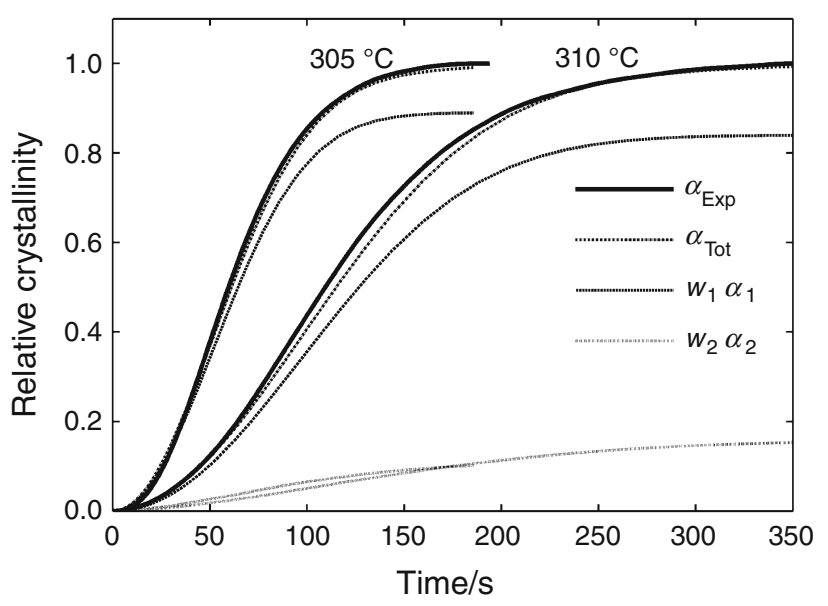

Fig. 8 Kinetic simulations of isothermal crystallization at 305 and $310^{\circ} \mathrm{C}$ 
isothermal numerical integration procedure was developed in Matlab ${ }^{\circledR}$ : the cooling curve is adequately approximated by a series of isothermal steps and the Runge-Kutta integration is used during each step. The variation of relative crystallization is calculated by the summation of transformed fraction during each elementary step.

Numerical results for a constant cooling rate of $-20{ }^{\circ} \mathrm{C} \min ^{-1}$ are shown in Fig. 9 (referenced as without ILT). The total relative crystallinity evolution is compared with the experimental result and the relative crystallinity contribution of each mechanism is plotted. If general sigmoidal shape is similar to experimental one, the predicted curves overestimate the crystallization kinetics. Indeed, as mentioned on experimental results, crystallization start temperatures $\left(T_{\text {start }}\right)$ change with non-isothermal cooling rate. As a matter of fact, nucleation is not instantaneous and an induction lag time (ILT) has to be introduced and considered during modelling.

The cooling rate dependent lag time related to $T_{\text {start }}$ was thus experimentally determined as a linear equation $T_{\mathrm{START}}=0.236 \times \frac{\mathrm{d} T}{\mathrm{dt}}+309.87$, and implemented in the model to re-simulate non-isothermal crystallization kinetics. Thanks to this modification, simulation results are quite in good agreement with experimental curves, in particular for $-20{ }^{\circ} \mathrm{C} \mathrm{min}^{-1}$ cooling (Fig. 9), but this procedure is still not effective for other conditions as shown for example in Fig. 10 for $-60{ }^{\circ} \mathrm{C} \mathrm{min}^{-1}$. Moreover, for all these cooling rates, the model predicts a significant contribution of the minor mechanism $\left(\alpha_{2}\right)$ whereas experimental observations do not exhibit a distinct secondary melting peek $\left(T_{\mathrm{m} 2}\right)$ as shown in Fig. 5.

In order to improve model capabilities, a non-isothermal kinetic parameter identification was performed using the Matlab ${ }^{\circledR}$ routine previously described and combined with an optimization procedure. Considering that nucleation and

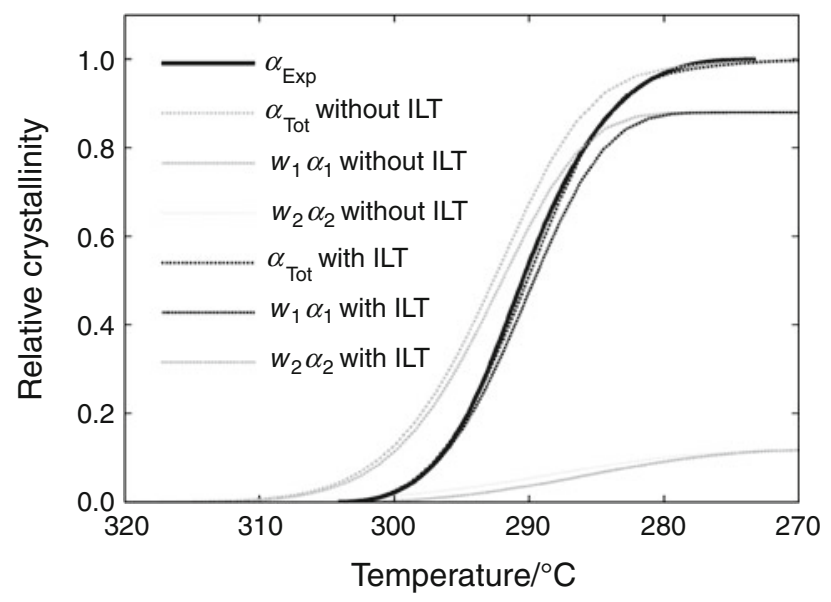

Fig. 9 Kinetic simulation of non-isothermal crystallization $-20{ }^{\circ} \mathrm{C}$ $\min ^{-1}$ with and without considering an induction lag time (ILT)

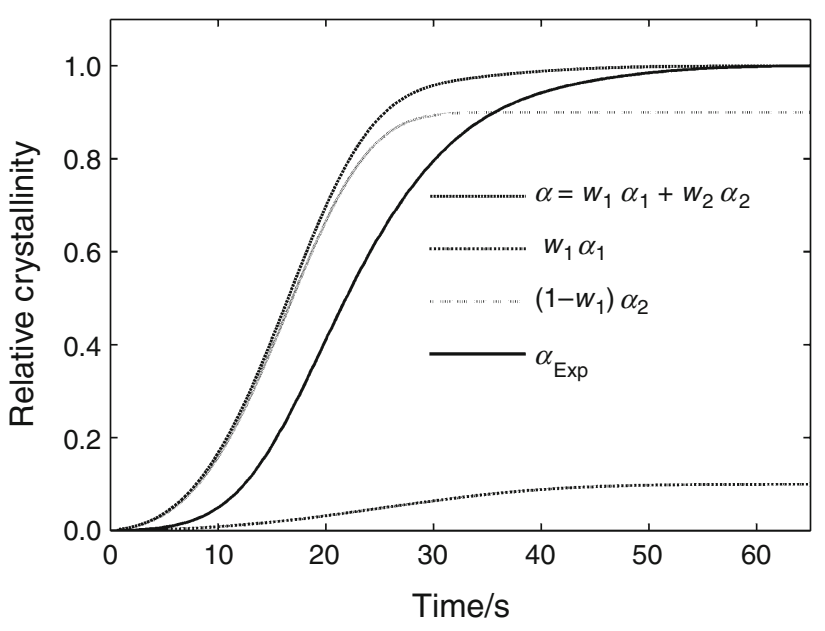

Fig. 10 Kinetic simulation of non-isothermal crystallization at $-60{ }^{\circ} \mathrm{C} \min ^{-1}$

growth mechanisms are only material dependent and do not depend on crystallization conditions, i.e. that values of $n_{1}$ and $n_{2}$ are fixed, the five parameters $E_{1}$ and $E_{2}$ (activation energies), $A_{1}$ and $A_{2}$ (pre-exponential factors) and $w_{1}$ (weighting factor of the first mechanism) were identified for all testing conditions (cooling rates from -3 up to $-100{ }^{\circ} \mathrm{C} \min ^{-1}$ ).

Results reported in Table 5 show that whatever the cooling rate, the activation energies of both mechanisms remain constant and equal to those obtained during the isothermal identification. On the contrary, slow cooling rates $\left(<10^{\circ} \mathrm{C} \min ^{-1}\right)$ have a strong influence on kinetic parameters $A_{1}$ and $A_{2}$, and surprisingly in such conditions, values of $A_{1}$ are higher than those obtained in isothermal conditions (cf. Table 4). Moreover mechanism 2 becomes preponderant in such conditions, i.e. up to $60 \%$ for $-3{ }^{\circ} \mathrm{C} \mathrm{min}^{-1}$, indicating that slow cooling rates favours the development of both crystallite types.

Comparison between numerical model and experimental results actually show a very good correlation whatever the cooling rate (Fig. 11). Contribution of each mechanism is shown in Fig. 12 for a cooling rate of $-3{ }^{\circ} \mathrm{C} \mathrm{min}{ }^{-1}$ : even

Table 5 Kinetic parameters for constant cooling rates

\begin{tabular}{llllll}
\hline $\begin{array}{l}\text { Cooling } \\
\text { rate/K } \mathrm{min}^{-1}\end{array}$ & $E_{1} / \mathrm{J} \mathrm{mol}$ & $E_{2} / \mathrm{J} \mathrm{mol}^{-1}$ & $A_{1}$ & $A_{2}$ & $w_{1}$ \\
\hline 3 & 1315.7 & 1050.0 & 1.60 & 0.20 & 0.4 \\
5 & 1315.3 & 1050.0 & 1.04 & 0.18 & 0.64 \\
7 & 1316.1 & 1049.2 & 1.00 & 0.26 & 0.68 \\
10 & 1316.0 & 1050.0 & 0.63 & 0.16 & 0.79 \\
20 & 1315.8 & 1049.1 & 0.64 & 0.20 & 0.88 \\
40 & 1316.0 & 1049.3 & 0.68 & 0.20 & 0.93 \\
60 & 1316.0 & 1050.0 & 0.63 & 0.16 & 0.97 \\
80 & 1315.9 & 1050.0 & 0.68 & 0.18 & 0.97 \\
100 & 1315.7 & 1049.1 & 0.68 & 0.16 & 0.96 \\
\hline
\end{tabular}




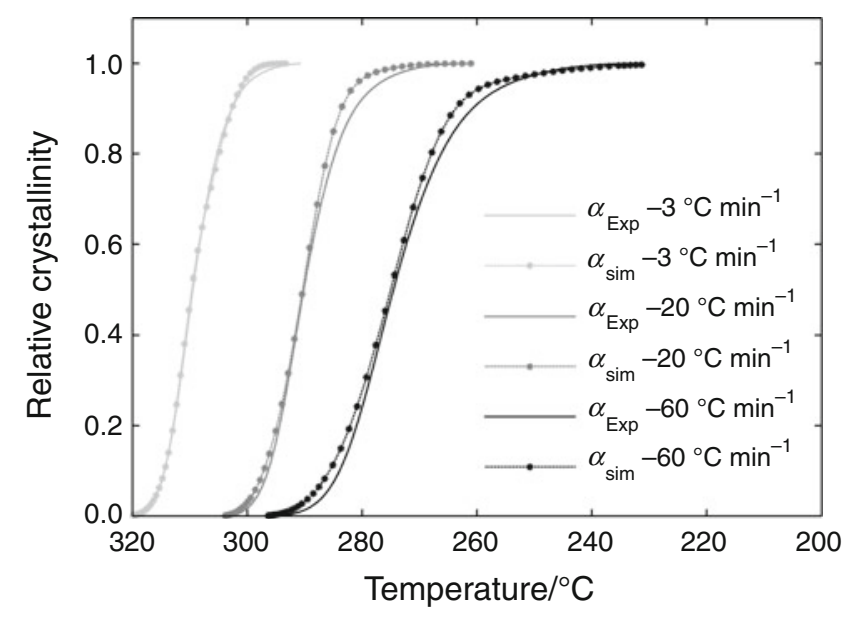

Fig. 11 Comparison of experimental crystallization data with model prediction for three cooling rates

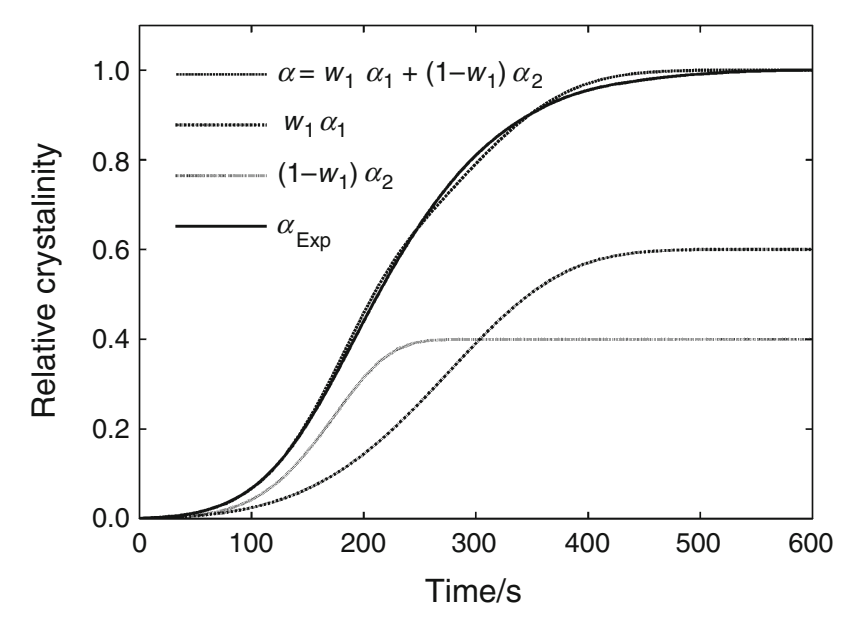

Fig. 12 Mechanisms contribution for $-3{ }^{\circ} \mathrm{C} \min ^{-1}$ cooling ramp

if mechanism 1 starts first, its contribution to final crystallinity is less important than mechanism 2 (only $40 \%$ ) which is quite different from isothermal crystallization where mechanism 1 is always preponderant.

\section{Discussion}

The here-proposed model supposes that PEEK crystallization is governed by two competing crystallization mechanisms satisfying the Avrami equation. Each mechanism is characterised by a $n_{\mathrm{i}}$ exponent and a kinetic parameter $K_{\mathrm{i}}$, which thermal sensitivity is considered as Arrhenius type. Using a differential form of the Avrami's law, the model can predict PEEK crystallization in both isothermal and non-isothermal cooling conditions with good accuracy. Nevertheless, parameters identification must be performed in both cases otherwise the crystallization prediction is not satisfactory.

Isothermal and non-isothermal identifications lead to the same values of $n_{1}, n_{2}, E_{1}$ and $E_{2}$. On one hand, this important result upholds the choice of two complementary mechanisms to model PEEK crystallization process, and, on the other hand, confirms that these parameters are only material dependent and do not depend on thermal conditions. According to Avrami's theory, the $n$ exponent characterises the kind of nucleation (homogeneous or heterogeneous), and the growth geometry (one-, two-, or three-dimensional growth). Mechanism 1, which $n_{1}$ exponent is 2.1 , would then induce crystallization with larger dimensionality than mechanism 2 , which $n_{2}$ exponent is only 1.7 . Regarding an homogeneous nucleation, such a low $\mathrm{n}$ exponent refers to a one-dimensional crystal growth and such growth is generally depicted as 'toothpicks placed on a water surface in increasing concentration'. This difference of mechanisms dimensionality agrees with the dual crystallization process described by Verma et al. or Latimmer et al. [15, 16] as a classical crystal nucleation and lamellae growth associated to mechanism 1 and an interlamellar phase associated to mechanism 2. Such a description, however, suggests a radical dimension difference between both crystals growth mechanisms that the identified $\mathrm{n}$ exponents do not clearly confirm.

Results also show that the weighting factor $w_{1}$ and crystallization kinetics $K_{\mathrm{i}}$ are the only temperature-dependent parameters governing PEEK crystallization. Parameters identification reveals that $A_{1}$ and $A_{2}$ remain constant during isothermal crystallization but are influenced by the cooling rate. The $A_{1}$ (resp. $A_{2}$ ) parameter decreases from 1.6 (resp. 0.2) to 0.68 (resp. 0.16) when increasing cooling rate from -3 to $-100{ }^{\circ} \mathrm{C} \mathrm{min}^{-1}$ (Fig. 13), indicating that mechanism 1 is thus much faster than mechanism 2 whatever the cooling condition. Similarly, identification of weighting factor $w_{1}$ systematically leads to different values and is both influenced by temperature and cooling rate. But beyond the large sensitivity of these three parameters, the comparison between non-isothermal and isothermal values displays contradictory effects.

Indeed, an isothermal crystallization condition could be considered as a lower limit of cooling rate and continuity could be expected between the values of isothermal identification and the values resulting from non-isothermal identification at low rate. Instead, the non-isothermal analysis reveals that mechanism 2 becomes the major crystallization process at low cooling rate $\left(w_{1}=0.4\right.$ for $-3{ }^{\circ} \mathrm{C} \min ^{-1}$ ) (Fig. 13) whereas isothermal results suggest that mechanism 1 widely remains the predominant crystallization process (Fig. 8).

In the same way, isothermal identification of $A_{1}$ and $A_{2}$ leads to values corresponding to $\mathrm{a}-7{ }^{\circ} \mathrm{C} \min ^{-1}$ cooling 

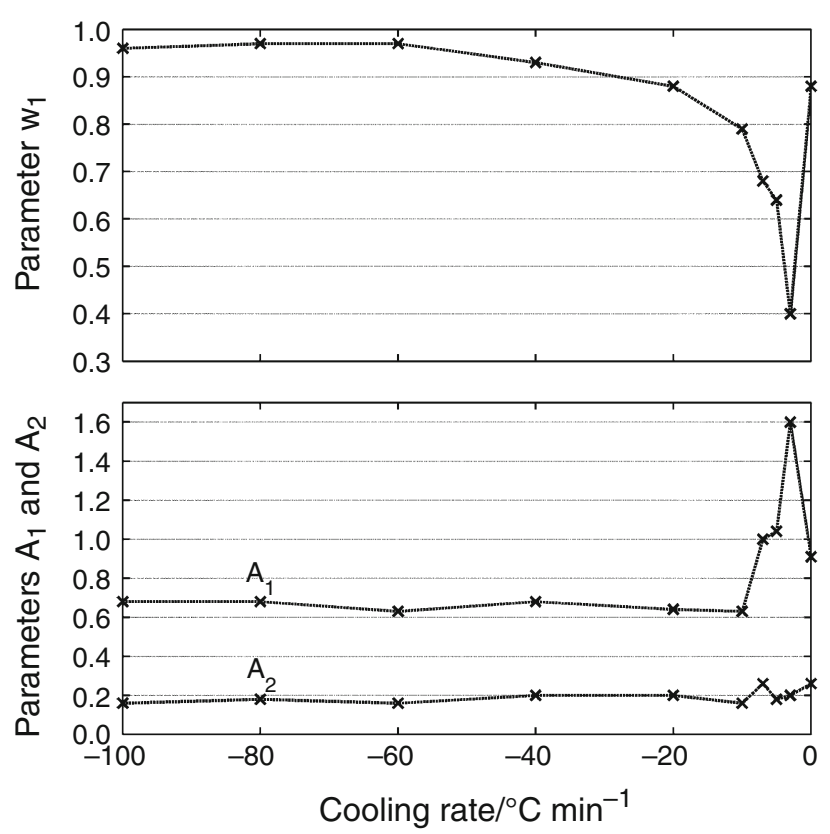

Fig. 13 Non-isothermal and isothermal (cooling rate $=0$ ) kinetic model parameters

rate and the continuity is not respected. As it can be seen in Fig. 3, $-7{ }^{\circ} \mathrm{C} \min ^{-1}$ crystallization occurs between 310 and $290{ }^{\circ} \mathrm{C}$ which exactly corresponds to the temperature range of the isothermal crystallization study. This let us suppose that $A_{1}$ and $A_{2}$ parameters may not necessarily depend only on the cooling rate but maybe also on the temperature range in which the crystallization occurs.

Otherwise, the testing method for isothermal crystallization study assumes that the previous rapid cooling step performed at $-200{ }^{\circ} \mathrm{C} \mathrm{min}{ }^{-1}$ does not influence isothermal PEEK Crystallization. Yet, this strong assumption must be reconsidered with regards to the contradictory values of the identified parameters. Indeed, even if DSC signal do not exhibit any crystallization enthalpy during this step, it may be possible that nucleation of mechanism 1 is initiated during cooling, which would favours mechanism 1 to occur during the isothermal step. This assumption is coherent with the weighting factor observed for high cooling rates: non-isothermal crystallization at constant cooling rate of $-100{ }^{\circ} \mathrm{C} \mathrm{min}{ }^{-1}$ leads to a weighting factor of 0.96. This inconsistency between isothermal and nonisothermal parameters is probably heightened for a polymer like PEEK that crystallizes very rapidly. As a consequence to improve further crystallization model it would be interesting to introduce a cooling rate nucleation model for mechanism 1, able to initiate the more or less growth of mechanism 1 crystallite types.

Finally, if high temperature (i.e. isothermal or low cooling rate) favours mechanism 2 to occur, the resulting crystalline structure still exhibits a low melting temperature
$\left(T_{\mathrm{m} 2}\right)$. Yet, both mechanisms lead to the same crystalline form and it thus suggests that both mechanisms are related.

\section{Conclusions}

The use of differential form of Avrami equation and considering that PEEK crystallization is induced by two complementary mechanisms has allowed to model with good accuracy non-isothermal and isothermal PEEK crystallization even if identification of model parameters must be performed in both conditions. If crystallization type is a material property, as denoted by the stability of the Avrami exponents $n_{\mathrm{i}}$ and activation energies $E_{\mathrm{i}}$ whatever crystallization condition, the weighting factor $w_{1}$ and the Arrhenius parameters $A_{1}$ and $A_{2}$ are largely influenced by thermal conditions. Moreover, both identifications lead to different trends suggesting that nucleation occurs during the rapid cooling prior to the isothermal step and therefore influences isothermal crystallization.

The whole set of results (double melting peak, nonisothermal parameters, dissymmetry of the $S$-shape relative crystallinity) thus indicates that the secondary mechanisms is favoured for slow cooling rates and isothermal crystallization, while main crystallization mechanisms contribution, even if this mechanism appears to be a faster phenomenon, increases with increasing the cooling rate.

Finally, this study also raises a new issue about how isothermal crystallization can be characterized experimentally for polymers that exhibit rapid crystallization, since isothermal crystallization is controlled by previous nucleation that may appear during the rapid cooling step.

Acknowledgements This work was carried out as part of the cooperative INMAT2 project and was financially supported by the Fond Unique Interministériel. The authors wish to thank the project partners for their contribution to the present work. Further thanks are addressed to the technicians of the Institut Clément Ader for their assistance in the experiments.

\section{References}

1. Gao SL, Kim JK. Cooling rate influences in carbon fibre/PEEK composites. Part 1. Crystallinity and interface adhesion. Comp Part A. 2000;31:517-30.

2. Gao SL, Kim JK. Cooling rate influences in carbon fibre/PEEK composites. Part III: Impact damage performance. Comp Part A. 2001;32:775-85.

3. Rudolf R, Mitschang P, Neitzel M. Induction heating of continuous carbon-fibre-reinforced thermoplastics. Comp Part A. 2000;31:1191-202.

4. Turnbull D, Fisher JC. Rate of nucleation in condensed systems. J Chem Phys. 1949;17:71-3.

5. Hoffman JD, Lauritzen JI. Crystallization of bulk polymers with chain folding - theory of growth of lamellar spherulites. J Res Nat Bur Stand. 1961;65A:297-336. 
6. Nakamura K, Watanabe T, Katayama K. Some aspects of nonisothermal crystallization of polymers. I. relationship between crystallization temperature, crystallinity, and cooling conditions. J Appl Polym Sci. 1972;16:1077-91.

7. Ziabicki A. Theoretical analysis of oriented and non-isothermal crystallization. Colloid Polym Sci. 1974;252:433-47.

8. Ozawa T. Kinetics of non-isothermal crystallization. Polymer. 1971;12:150-8.

9. Patel RM, Sprueill JE. Crystallization kinetics during polymer processing: analysis of available approaches for process modeling. Polym Eng Sci. 1991;31:730-8.

10. Le Goff R, Poutot G. Study and modeling of heat transfer during the solidification of semi-crystalline polymers. Int J Heat Mass Tran. 2005;48:5417-30.

11. Malkin AY, Beghishev VP, Keapin IA. General treatment of polymer crystallization kinetics. Part I. A new macrokinetic equation and its experimental verification. Polym Eng Sci. 1984;24:1396-401.

12. Supaphol P. Application of the Avrami, Tobin, Malkin and Urbanovici-Segal macrokinetic models to isothermal crystallization of syndiotactic polypropylene. Thermochim Acta. 2001;370:37-48.

13. Lee Y, Porter RS. Double-melting behavior of poly(ether ether ketone). Macromolecular. 1987;20:1336-41.

14. Blundell DJ, Osborn BN. The morphology of poly(aryl-etherether-ketone). Polymer. 1983;24:953-8.

15. Latimmer MP, Hobbs JK, Hill MJ. On the origin of the multiple endotherms in PEEK. Polymer. 1992;33:3971-3.

16. Verma RK, Velikov V, Kander RG. SAXS studies of lamellar level morphological changes during crystallization and melting in PEEK. Polymer. 1996;37:5357-65.

17. Bessard E, De Almeida O, Bernhart G. Melt state behaviour of PEEK and processing window interpretation for fast compression moulding process. In: Chinesta F, Chastel Y, El Mansori M, editors. AIP conference proceedings. Paris: AMPT; 2011.
18. Cheng SZD, Cao MY, Wunderlich B. Glass transition and melting of PEEK. Macromolecular. 1986;19:1868-76.

19. Basset DC, Olley RH, Al Raheil IAM. On crystallization phenomena in PEEK. Polymer. 1988;29:1745-54.

20. Velisaris C, Seferis J. Crystallization kinetics of polyetheretherketone (PEEK) matrices. Polym Eng Sci. 1986;26: 1574-81.

21. Cebe P. Application of the parallel Avrami model to crystallization of PEEK. Polym Eng Sci. 1988;28:1192-7.

22. Tan S, Su A, Luo J. Crystallization kinetics of poly(ether ether ketone) (PEEK) from its metastable melt. Polymer. 1999; 40:1223-31.

23. Chao SC, Chen M, Chung CT. Isothermal crystallization and melting behavior of short carbon fiber reinforced poly(ether ether ketone) composites. J Polym Res. 1998;5:221-6.

24. Wei CL, Chen M, Yu FE. Temperature modulated DSC and DSC studies on the origin of double melting peaks in poly(ether ether ketone). Polymer. 2003;44:8185-93.

25. Avrami M. Kinetics of phase change. I general theory. J Chem Phys. 1939;7:1103-12.

26. Supaphol P, Spruiell JE. Application of the Avrami, Tobin, Malkin and simultaneous Avrami macrokinetic models to isothermal crystallization of syndiotactic polypropylenes. J Macromol Sci. 2000;39:257-77.

27. Malek J. Kinetic analysis of crystallization processes in amorphous materials. Thermochim Acta. 2000;355:239-53.

28. Trende A, Astrom BT, Wöginger A. Modelling of heat transfer in thermoplastic composites manufacturing: double-belt press lamination. Comp Part A. 1999;30:935-43.

29. Cebe P. Non-isothermal crystallization of poly(ether ether ketone) aromatic polymer composite. Polym Comp. 1988;9: $271-9$. 